\title{
Apuntes sobre la objetivación del 'cuerpo' como 'naturaleza': del ego conquiro al ego cogito
}

\author{
Patricio Lepe Carrión \\ Universidad Católica de Temuco
}

http://dx.doi.org/10.5209/rev_NOMA.2014.v42.n2.48777

Emmanuel C. Eze, en su artículo "Answering the Question, 'What Remains of Enlightenment?"' (2002), nos señala que en la historiografía filosófica, es casi una costumbre generalizada describir la ilustración como un conjunto de fenómenos exentos de todo rasgo racial, de exclusión de género o de sexismo; y que frente a estas ideas dominantes de pureza adjudicadas al siglo de la razón, se coloca la otra idea, comúnmente aceptada también, de que la llustración debiera remitirse a las concepciones que resurgieran durante el Renacimiento en torno al Hombre y su protagonismo en el cosmos. Descartes, Galileo y Newton, se tornarán en los hijos ilustres de la nueva historia del pensamiento occidental, como los fundadores de una nueva manera de entender el mundo: la Modernidad -o de la 'segunda etapa de la Modernidad' diremos nosotros con Dussel-1. $Y$ es en este marco -como veremos más adelante- donde la ciencia comenzará a tomar ese espíritu de 'rigurosidad' tan propio del siglo XVII, y en que se autodefinirá como el espacio sagrado desde el cual todo podrá ser observado y medido, es decir, como un lugar neutro de análisis y clasificación.

Paralelamente al re-descubrimiento de una idea de humanidad anclada en los ideales renacentistas, surge en Europa durante el siglo XVII, el redescubrimiento del 'salvaje' como un modelo de 'in-civilidad' que, de forma muy interdependiente, vendrá a contrarrestar -insisto, de manera equilibrada- al modelo mismo de civilización ilustrada.

El 'ego cogito' (Yo pienso) cartesiano, que representa -a modo de estandarte de guerra- la 'segunda etapa de la Modernidad', sólo es comprendido a partir de la incuestionable noción del 'ego conquiro' (Yo conquisto) como ideal de subjetividad iniciado durante el eufemísticamente llamado 'encuentro' entre europeos y gente del 'nuevo mundo' en el siglo XV. La proto-historia del ego cogito es, sin lugar a dudas, el ego conquiro en tanto configurador de la identidad del nuevo sujeto burgués (blanco, varón, propietario, trabajador, ilustrado, heterosexual), a partir de las crónicas que viajeros del mundo

\footnotetext{
${ }^{1}$ Por más tentador que sea, no podemos detenernos a desmitificar esta afirmación. Sin embargo remitimos a las obras de Enrique Dussel, sobre los antecedentes coloniales de la Modernidad, o de cómo el siglo XVII -con Descartes, como ícono de la inteligencia moderna-, no sería sino el "fruto de un siglo y medio de Modernidad: son efecto y no punto de partida”. La Modernidad tendría sus comienzos y primeros impulsos durante la conquista de América (en el ego conquiro que antecede al ego cogito). La revolución industrial y la Ilustración, se presentarían como profundizaciones de la segunda etapa de la Modernidad que emerge en el siglo XVII (cfr. Dussel, 2000: 46). Para profundizar sobre el concepto de Modernidad en Dussel, y su particular manera de interpretar a Descartes, puede consultarse el excelente artículo: (Dussel, 2008).
} 
elaboraban respecto al 'salvaje' americano, asiático y africano. El mundo hispanoamericano no sólo aportará con la mano de obra y materias primas, sino también, con los fundamentos epistemológicos, morales y políticos de la cultura moderna europea (cfr. Castro-Gómez, 2005b: 48, 67).

El escepticismo metódico característico del sistema cartesiano, que media en las relaciones del yo con el mundo, en la existencia de este último y en la veracidad correctiva de las matemáticas y la lógica; habría sido antecedido por otro tipo de escepticismo, no menos radical, que ponía en cuestión la 'calidad humana', es decir, la 'humanidad', de los colonizados; esto es, si el escepticismo cartesiano vendría a contribuir en la división metafísica de la historia del pensamiento occidental, entre un objeto-mundo por un lado, y por otro el sujeto-yo-racional que, vendría a sostener y a justificar la existencia del primero; el escepticismo colonial que, antecede a la comprensión que Europa tendrá sobre sí misma, sostiene la diferencia en base a un Conquistador y un Conquistado, uno más humano que el otro -por supuesto-, y por lo tanto, más real, o más verdadero:

"La 'Conquista' es un proceso militar, práctico, violento que incluye dialécticamente al Otro como 'lo Mismo'. El Otro, en su distinción, es negado como Otro y es obligado, subsumido, alienado a incorporarse a la Totalidad dominadora como cosa, como instrumento, como oprimido, como 'encomendado', como 'asalariado' (en las futuras haciendas), o como africano esclavo (en los ingenios de azúcar u otros productos tropicales)." (Dussel, 1992)

El ego europeo moderno, en su conformación de identidad, vuelca sus raíces en la 'herida o diferencia colonial' que, la antigua clasificación de las sociedades entre lo 'civilizado y lo 'bárbaro', habría dejado una profunda huella en las tierras del 'nuevo mundo'. Enrique Dussel, ejemplifica con Hernán Cortés, en tanto hidalgo endiosado por los nativos, el primer momento de la historia europea en que, el 'viejo continente' se constituye como 'Amo y Señor del mundo' (Voluntad de poder), y hace hincapié en comprender la instauración de la 'actitud imperial' en tanto 'hombre imperial-conquistador':

"La primera 'experiencia' moderna fue de la superioridad cuasidivina del "Yo" europeo sobre el Otro primitivo, rústico, inferior. Es un 'Yo' violento-militar que "codicia", que anhela riqueza, poder, gloria." (Dussel, 1992).

No es de extrañar entonces que durante el siglo XVII, justamente cuando Holanda pasa a ser el centro del sistema-mundo moderno, Descartes, desde distintas ciudades como Amsterdam, Leiden, Egmond de Hoef, o Egmond Binnen2 -tierras holandesas donde residió cerca de veinte años-, hable en un

\footnotetext{
${ }^{2}$ Holanda se emancipa de España en 1610, y junto a Francia e Inglaterra, se convierte en el centro del nuevo sistema-mundo moderno, se convierten en oligarquías comerciales con un fuerte apoyo naval y terrestre; se abren paso por el Atlántico, sobretodo a partir de la firma del tratado de Wesfalia (1648) que pone fin la guerra de los treinta años. España pierde el poder de controlar el Atlántico, y los comerciantes ingleses, holandeses y franceses, consiguen adoptar una extensa red de piratería y contrabando que, va a
} 
plano epistemológico, como reflejo de un plano político (y colonial), de una res cogitans y res extensa, como dos regiones separadas e irreconciliables; como veíamos, tenía este 'escepticismo maniqueo' un antecedente claro en el siglo XV durante la racionalidad colonial europea3, o de cómo el hombre europeo se posicionaba frente al mundo como totalidad:

"[...] la condición de posibilidad política, económica, cultural y social para que un sujeto asuma la arrogancia de hablar como si fuera el ojo de Dios, es el sujeto cuya localización geopolítica está determinada por su existencia como colonizador/conquistador, es decir, como Ser imperial" (Grosfoguel, 2007)

Con el solipsismo de Descartes, se abrirá una nueva ventana a la 'objetivización' del 'cuerpo' como 'naturaleza', o como exterioridad frente al 'espíritu', posibilitando su instrumentalización en la teorización científica.

Es muy común presentar a Descartes como el inaugurador de la Modernidad; pero a decir verdad, Descartes no inaugura nada; la actitud objetivante frente a la naturaleza, o la radical separación del cuerpo frente al no-cuerpo, es una idea que se desarrolla como un proceso de larga duración en la historia del pensamiento, sobre la base de la superioridad del 'alma' respecto al 'cuerpo'; un terreno que ya venía siendo discutido desde los siglos XII y XIII por la teología escolástica, o incluso siglos antes por la filosofía estoico-aguntiniana, o más aún por las teorías del alma en Platón y Aristóteles; sin embargo, en Descartes, asistimos a una relectura y formulación filosófica de dicha distinción: lo que antes era una co-pertenencia entre cuerpo y alma, o cuerpo y no-cuerpo, a partir del siglo XVII, se transformará en una actitud muy radical en la separación 'insalvable' entre 'razón-sujeto' por un lado, y de 'cuerpo' por el otro (cfr. Castro-Gómez, 2007: 82; cfr. Quijano, 2000).

Quijano (cfr. 2000: 224), nos recuerda aquella frase que escribiera Sarmiento en las paredes de los baños de Zonda en 1840: "On ne tue point les idées". Frase que Sarmiento toma de las palabras enunciadas por Hippolyte Fortoul antes de ser degollado, y que reproduce en la advertencia a su obra 'Barbarie y Civilización'.

Sin importar si fue comprendida o no en su momento, Quijano nos señala que dicha expresión, traducida como "Bárbaros, las ideas no se degüellan", puede fácilmente encontrar su origen en el maniqueísmo cartesiano: las ideas 'deben' ser respetadas, en cambio el cuerpo, puede ser torturado, triturado y muerto.

La 'razón-sujeto' será entonces la única capaz de conocimiento racional; despojando al cuerpo de todo vínculo con el alma, y con ello, la objetivación del

enriquecer de gran manera a estos países; Amsterdam, será la nueva capital del comercio europeo que reemplazará a Sevilla (cfr. Castro-Gómez, 2005a: 97-98).

${ }^{3}$ Según Franz Fanon, el mundo colonial es un mundo maniqueo, un mundo cortado en dos, que llega al extremo de deshumanizar al colonizado, lo animaliza; emplea en contra del dominado un lenguaje zoológico, que lo instrumentaliza e inmoviliza, convirtiéndolo en la 'quintaesencia del mal'; las colonias son infértiles de bienestar, de valores, de una ética; sus costumbres, ritos, mitos, etc., no son sino señal de su indigencia, de su precariedad, de su barbarie (cfr. Fanon, 1963). 
cuerpo como cosa de estudio, como naturaleza digna de ser estudiada por el sujeto, al cual ya se encuentra fuera de toda relación. El 'cuerpo' -en última instancia-, del mismo modo que el colonizado, se vuelve domable y explotable; idea que atravesará muy fuertemente el pensamiento filosófico y científico (y por ende, político) de los siglos venideros; la idea de raza -por ejemplo, y su respectiva teorización, tendrá como pilar fundacional o anterioridad necesaria, esta objetivación de los cuerpos como 'naturaleza' observable4.

El mito del 'estado de naturaleza', y de su consecuente 'irracionalidad', legitimará la visión del otro no-europeo como un 'estado de barbarie'; el 'ego cogito', ocultará en términos epistemológicos un complejo problema ontológico:

"Yo pienso (otros no piensan o no piensan adecuadamente), luego soy (otros no son, están desprovistos de ser, no deben existir o son dispensables)" (Maldonado-Torres, 2007: 144)5.

El 'ego conquiro' se convierte entonces en "condición de posibilidad" del 'ego cogito', consolidando una subjetividad e individualidad europea como superior, y de la anulación o reducción del 'otro' por la conquista (cfr. Restrepo y Rojas, 2010: 160); y el surgimiento del 'ego cogito' en su separación 'absoluta' de la corporalidad, será también determinante en la configuración de las relaciones entre las distintas culturas: América, Asia y África, se convertirán en los 'cuerpos' exóticos y coloridos de la 'racionalidad-europea', dignos de estudio, y objetos de una cartografía geopolítica de una emergente mirada científica (cfr. Eze, 2002; cfr. Maldonado-Torres, 2007; cfr. Quijano, 2000).

\section{Referencias bibliográficas}

CASTRO-GÓMEZ, S. (2005a), La hybris del punto cero: ciencia, raza e ilustración en la Nueva Granada (1750-1816), (Bogotá: Pontificia Universidad Javeriana).

- (2005b), La poscolonialidad explicada a los niños, (Popayán: Editorial Universidad del Cauca - Instituto Pensar, Universidad Javeriana).

- (2007), 'Decolonizar la Universidad. La hybris del punto cero y el diálogo de saberes', en Grosfoguel, Santiago Castro-Gómez y Ramón (ed.), El giro decolonial. Reflexiones para una diversidad epistémica más allá del capitalismo global (Bogotá: Siglo del Hombre Editores), 79-91.

Dussel, Enrique (1992), 1492. El encubrimiento del otro: Hacia el origen del "mito de la modernidad", (México: Editorial Cambio XXI).

- (2000), 'Europa, modernidad y eurocentrismo', en (comp.), Edgardo Lander (ed.), La colonialidad del saber: eurocentrismo y ciencias sociales. Perspectivas latinoamericanas. (Buenos Aires: CLACSO), 41-54.

\footnotetext{
${ }^{4}$ Quijano también nos refiere a la intrínseca dependencia del surgimiento del concepto de raza con la histórica formulación del cuerpo como objeto, o de la naturalización e irracionalidad inherente en la corporalidad. El cuerpo como objeto, o como campo de prácticas, será el terreno sobre el cual se construirá la idea de raza, como será durante el siglo XIX el caso del Conde de Gobineau (cfr. Quijano, 2000).

${ }^{5}$ Sobre esta negación ontológica y epistemológica de los no-europeos que subyace al discurso de la Modernidad, y que los pensadores decoloniales han denominado como 'colonialidad del ser' y 'colonialidad del saber', puede consultarse: (Lander, 2000; Maldonado-Torres, 2006, 2007; Mignolo, 2006)
} 
- (2008), 'Meditaciones anti-cartesianas: sobre el origen del anti-discurso filosófico de la modernidad', Tabula Rasa, (núm. 9).

EZE, E. C. (2002), 'Answering the Question,"What Remains of Enlightenment"?', Human Studies, 25 (núm. 3).

FANON, F. (1963), Los condenados de la tierra, (trad. Campos, Julieta) (Mexico: Fondo de cultura economica México).

GROSFOGUEL, R. (2007), 'Descolonizando los universalismos occidentales: el pluri-versalismo transmoderno decolonial desde Aimé Césaire hasta los Zapatistas', en Grosfoguel, Santiago Castro-Gómez y Ramón (ed.), El giro decolonial. Reflexiones para una diversidad epistémica más allá del capitalismo global (Bogotá: Siglo del Hombre Editores), 63-78.

LANDER, E. (ed.), (2000), La colonialidad del saber: eurocentrismo y ciencias sociales: perspectivas latinoamericanas (Buenos Aires: Consejo Latinoamericano de Ciencias Sociales - CLACSO).

MALDONADO-TORRES, N. (2006), 'La topologia del ser y la geopolítica del saber: modernidad, imperio, colonialidad', en Walter Mignolo, Freya Shiwy y Nélson Maldonado-Torres (ed.), Des-colonialidad del ser y el saber (videos indígenas y los limites coloniales de la izquierda) en Bolivia (Buenos Aires: Ediciones del Signo), 63-130.

- (2007), 'Sobre la colonialidad del ser: contribuciones al desarrollo de un concepto', en Grosfoguel, Santiago Castro-Gómez y Ramón (ed.), El giro decolonial. Reflexiones para una diversidad epistémica más allá del capitalismo global (Bogotá: Siglo del Hombre Editores), 127-167.

MIGNOLO, W. (2006), 'La descolonización del ser y del saber', en Walter Mignolo, Freya Shiwy y Nélson Maldonado-Torres (ed.), Des-colonialidad del ser y el saber (videos indígenas y los limites coloniales de la izquierda) en Bolivia (Buenos Aires: Ediciones del Signo), 25-30.

QUIJANO, A. (2000), 'Colonialidad del poder, eurocentrismo y América Latina', en (comp.), Edgardo Lander (ed.), La colonialidad del saber: eurocentrismo y ciencias sociales. Perspectivas latinoamericanas. Buenos Aires: CLACSO (Buenos Aires: CLACSO), 201-246.

RESTREPO, E. y ROJAS, A. (2010), Inflexión decolonial: Fuentes, conceptos y cuestionamientos, (Popayán, Colombia: Editorial Universidad del Cauca). 